\title{
A INTERAÇÃO NATURANTE ENTRE O DEMIURGO E O MUNDO, A QUESTÃO DOS “DOIS TIPOS DE MATÉRIA” E A NATUREZA DA “IMPLANTAÇÃO” DA ALMA NO CORPO
}

Edrisi Fernandes* edrisi@email.com

RESUMO Em seu Comentário ao Timeu, Proclo diz que em algumas ocasiões Platão fala de um modelo (a partir do qual o mundo é criado) que é idêntico ao Demiurgo, enquanto noutras ocasiões sugere que o modelo é distinto do Demiurgo. Aqui, identidade e diferença remetem à semelhança ou dessemelhança com o inteligível, identificado com a eternidade (estabilidade; fixidez). Ora, Platão também fala no Timeu que o Cosmos é bonito e seu Construtor (o Demiurgo) é bom porquanto fixou a vista no modelo eterno. Se perguntarmos o que é engendrado quando o Demiurgo fixa a vista num modelo que não lhe é idêntico, encontramos a resposta no Timeu: inveja, defeitos, desordem, limitação quanto à inteligência e à alma, incompletude, feiúra e imperfeição. Plotino, por sua vez, menciona (Enéadas, II.4), a existência de dois tipos de matéria, inteligível e sensível. A matéria inteligível ou divina equivale à "Díade indefinida", identificada com a processão do Noûs. Para Plotino, apesar de a matéria inteligível ser eterna e imutável sua archế é constituída por diferença e movimento - condições que preparam a naturação da matéria sensível. Para Proclo, a Alma, desdobramento do Noûs, faz a mediação entre o Intelecto, a matéria inteligivel e a matéria sensivel. Diversos intérpretes parecem ter entendido a matéria inteligível como matéria da Alma, e para explicar a interação entre o inteligível e o sensível muitas teorias surgiram a

* Médico e professor colaborador de Filosofia na UFRN. Recebido em 15/01/2010 e aprovado em 22/3/2010

KRITERION, Belo Horizonte, nº 122, Dez./2010, p. 617-635. 
respeito da constituição da matéria inteligível e sobre a natureza do "veículo" ou "veículos" que estariam associados à "descida" e encarnação da Alma.

Palavras-chave demiurgia, ontogênese, matéria inteligivel, matéria sensivel, ochêma, ochếmata.

ABSTRACT In his Commentary on the Timaeus Proclus says that in some occasions Plato speaks of a model (from which the world is created) that is identical to the Demiurge while in other occasions he suggests that the model is distinct from the Demiurge. Here, identity and difference refer to the similarity with or dissimilarity from the intelligible One, identified with eternity (stability; fixedness). However, Plato also speaks in the Timaeus that the Cosmos is pretty and its Constructor (the Demiurge) is good inasmuch as He fixed his sight in the perpetual model. If we ask what is produced when the Demiurge fixed his sight in a model that it is not identical to Himself, we find the reply in the Timaeus: envy, defects, disorder, limitation regarding intelligence and the soul, incompleteness, ugliness, and imperfection. Plotinus, on his turn, mentions (Enneads, II.4) the existence of two types of matter, intelligible and sensible. The intelligible or divine matter is equivalent to the "indefinite Dyad", identified with the procession of the Noûs. For Plotinus, though the intelligible matter is eternal and invariant, its archế is constituted by difference and movementconditions that prepare the naturation of sensible matter. For Proclus, the Soul, an unfolding of the Noûs, mediates between the Intellect, intelligible matter and sensible matter. Many interpreters seem to have understood inteligible matter as the matter of the Soul, and to explain the interaction between the intelligible and the sensible many theories have appeared regarding the constitution of intelligible matter and about the nature of the "vehicle" or "vehicles" that would be associated with the Soul's "descent" and incarnation.

Keywords demiurgy, ontogenesis, intelligible matter, sensible matter, ochêma, ochếmata.

\section{A interação naturante entre o Demiurgo e o Mundo}

Em seu Comentário ao Timeu1, ao tentar responder à pergunta sobre "se o Modelo do Universo está no Demiurgo principalmente (en autối prốtoi) 
[como quer Plotino ${ }^{2}$, ou depois dele [como quer (Cássio) Longino 3 , ou antes dele [como quer Porfírio $\left.{ }^{4}\right]^{\prime 5}$ - questão que acompanha a indagação sobre se existe alguma classe de Inteligíveis intermediários entre o Uno e o Demiurgo - Proclo sugere ${ }^{6}$, reconhecidamente aceitando as lições de seu mestre Siriano 7 , que Platão (Timeu, 29e1-3) "parece manifestar a identidade ${ }^{8}$ do Demiurgo com o Modelo" (324.9) enquanto noutras ocasiões (Tim., 30c3-6; 39e7-9) teria deixado transparecer que o Demiurgo é distinto ${ }^{9}$ do Modelo ${ }^{10}$. Respondendo, então, à pergunta que formulara acerca de estar o Modelo do Universo no Demiurgo, ou antes, dele, ou depois dele, Proclo deixa de lado a última possibilidade (aquela cogitada por Longino) e fica com duas hipóteses $^{11}$ : se o Modelo é idêntico ao Demiurgo, este é igual aos Inteligíveis e não os governa - esta função pertence ao "primeiro deus (prốtos theos)", o Bem ${ }^{12}$ -; se o Modelo é anterior ao Demiurgo, este é inferior ao Bem, que rege todos os Inteligíveis. Como aponta Michael Share ${ }^{13}$, "Proclo acredita que esses dois pontos de vista estão presentes no Timeu e, portanto, que ambos estão corretos quando propriamente entendidos".

Conforme Proclo, o Modelo está ao mesmo tempo acima do Demiurgo, "sob um modo inteligível (noêtốs)", e no Demiurgo, "sob um modo intelectivo (noêrỗs)"114. Noutras palavras, "existem dois Modelos; um é inteligível, outro é intelectivo (tò mèn noêtón esti, tò dè noerón); um é anterior ao Demiurgo, [sendo] primariamente eterno e unificado e abarcador de todos os Viventes Inteligíveis, o outro existe no Demiurgo, abrangendo de um modo unificado toda a série (arithmós) das Formas demiúrgicas ${ }^{15}(\ldots)$ "16. Trata-se de uma relação em dois graus de inteligibilidade, sendo que no nível inteligível o intelecto, o ser (ontos) e o existir (einai) são idênticos, mas tornam-se distintos

2 Festugière e Runia associam essa passagem à En., III.9.1, onde Plotino interpreta o Timeu, 39c.

3 Longin: Fragments, Art rhétorique, ed. Patillon e Brisson (LONGIN, 2001), Fr. 19; Proclo, In Tim., I.306.32307.14.

4 Porphyrii in Platonis Timaeum Comentariorum Fragmenta, ed. Sodano (PORFIRIO, 1964), Fr. 43.

5 In Tim., I.323.1-3, remetendo a 322.18 e ss.

6 In Tim., I.323.23 até 324.14. O raciocínio de Proclo nessa passagem é bem esmiuçado em Alain Lernould. Physique et Théologie. Lecture du Timée de Platon par Proclus. Villeneuve d'Asq (Nord): Presses Universitaires du Septentrion, 2001, p. 281-286.

7 In Tim., I.322.18-323.22.

8 "Sob um modo intelectivo [noêrỗs]" (In Tim., I.323.22).

9 "Sob um modo inteligível [noêtỗs]" (In Tim., I.323.22).

10 In Tim., I.323.24-324.4.

11 In Tim., II.359.30-360.2.

12 Cf. In. Tim., III.359.22 e ss.

13 PROCLUS, 2008, p. 220 n. 41.

14 In Tim., I.323.20-22.

15 In Tim., I.203.19; Formas criadoras em III.103.11. Cf. as Formas e Princípios racionais demiúrgicos (toîs eidesi kaì toî lógois toîs dêmiourgikoîs) na Theol. Plat. V.16, 55.16-56.3.

16 In Tim., II.360.17-21. 
no nível intelectivo. Nas palavras de Siorvanes ${ }^{17}$, pela metafísica platônica o ser e a essência tornam-se menos reais e mais fenomênicos quando surge uma distinção entre eles; conforme Simplício (In phys., 773.20-6), isso se dá quando se passa da natureza una [de ser um (tô̂ henòs)] para a natureza unificada (hênômenê) de um todo com partes.

De acordo com Proclo ${ }^{18}$, Platão parece manifestar uma identidade do Demiurgo com o Modelo Inteligível, a partir do qual o mundo é criado, quando diz que "Ele era bom e, naquilo que é bom - no que quer que seja isso - jamais se forma qualquer sentimento de inveja (phthónos) ${ }^{19}$ : como ele era, portanto, livre de inveja [= generoso], ele quis que todas as coisas nascessem com a maior semelhança possível com ele mesmo (paraplếsia heautồi)" (Timeu, 29e1-3). Platão teria deixado transparecer uma diferença entre o Demiurgo e o Modelo quando falou: "À semelhança de quais dos Viventes o Demiurgo fabricou o mundo? Longe de nós essa indignidade que ele o haja feito semelhante a algum daqueles que são apenas partes, mas postulemos que o mundo é absolutamente semelhante a esse Vivente (zốion $)^{20}$ do qual todos os viventes, tomados individualmente ou por espécies, são as partes ${ }^{21}$ " (Timeu, 30c4 e ss.). Uma diferença entre o Demiurgo e o Modelo apareceria ainda na seguinte passagem: "Na medida, portanto, em que o Intelecto contempla as Formas imanentes naquele que é o Vivente ${ }^{22}$, em tal número e com tais qualidades, foi com tais qualidades e em tal número que ele resolveu que este Universo devia também contê-lo" (Timeu, 39e 7-9) ${ }^{23}$. Podemos, portanto, concordar com Schelling que "por ser o mundo visível a réplica de um mundo ideal, seguese que deve haver no fundamento deste (zu Grunde liegen müße) a ideia de um zỗion (um zốion noêtón)" ${ }^{24}$. Na Teologia Platônica (V.16, 55.18), recordando o Timeu (31b1), Proclo chama o "Vivente do qual todos os viventes são as partes" de "o Vivente completo ${ }^{25}$ que abrange os modelos primários e inteligíveis" (tò pantelès zốion tò tỗn prôtístôn kai noêtô̂n paradeigmáton perilêptikón).

17 SIORVANES, 1996, p. 162.

18 In Tim., I.323.23 até 324.14.

19 Cf. Fritz-Gregor Herrmann, "Phthónos in the World of Plato's Timaeus". Em: D. Konstan e N. K. Rutter (eds.), Envy, Spite and Jealousy. The Rivalrous Emotions in Ancient Greece. Edinburgo: Edinburgh University Press, 2003, pp. 53-83; David Konstan, The Emotions of the Ancient Greeks. Toronto: University of Toronto Press, 2006, cap. 11, "Jealousy", pp. 219-244.

20 Proclo entende esse Vivente como "o Vivente essencial (to ousiỗdes Zỗion)", a Alma do Mundo.

21 Na tradução de Carlos Alberto Nunes (PLATÃO, 2001, p. 67) "o mundo, acima de tudo, se parece (...) com o [Vivente] que abrange todos os animais individualmente considerados ou por gêneros".

22 Na tradução de Carlos Alberto Nunes (PLATÃO, 2001, p. 76), "no animal que verdadeiramente existe".

23 Texto interpretado por Plotino em En., III.9.1.

24 SCHELLING, 1994, p. 29.

25 "Vivente-em-si (autozỗion)" duas linhas abaixo (V.16, 55.20). 
Tentaremos ver agora de que modo a questão dos dois tipos de interação naturante entre o Demiurgo e o mundo - a saber, através da semelhança com o Modelo Inteligível que lhe seria superior ou através da semelhança com o "Vivente completo" que lhe seria conatural - associou-se indiretamente no pensamento procleano à ideia da naturação de dois tipos de matéria, uma que seria resultado da interação inteligível do Demiurgo com um Modelo que the estaria acima, a matéria inteligível, e outra, a matéria sensível, que seria resultado da interação intelectiva do Demiurgo com um Modelo que lhe seria interior.

\section{A questão dos "dois tipos de matéria" e sua relação com a alma do mundo}

Para Schelling, quando Platão fala do mundo como "um Vivente dotado de Alma dotada de Intelecto (zốion empsychon ennoun)" (Timeu, 30c) estaria falando de duas instâncias da Alma do Mundo, definidas no seguinte processo: "Ele [= o Demiurgo] reuniu o Intelecto à Alma do Mundo (originária), e essa Alma do Mundo (agora racional) à matéria etc." ${ }^{26}$. Por uma extrapolação desse raciocínio mediante o estudo do comentário procleano ao Timeu podemos dizer que o Demiurgo, ao reunir o Intelecto (superior) à Alma do Mundo (originária e conatural a Si) [movimento 1], cria um zỗion noêtón distinto de $\mathrm{Si}$ [movimento 2], espécie de "matéria inteligível" que alojaria as Formas imanentes a partir da qual são posteriormente modelados ${ }^{27}$ os entes sensíveis. Isso é confirmado pela leitura que Proclo faz de uma passagem dos Oráculos Caldeus (In Tim., I.451.19-22; Fr. 34 Des Places) onde a matéria é apontada como gerada ${ }^{28}$ desde a "Fonte das fontes (pêgề pêgốn)" "29 [- literalmente, "dali (enthen)"]. De modo a preservar o estatuto de $\operatorname{archôn}{ }^{30}$ para a matéria - ao menos para a

26 "Er vereinigte mit der (ursprünglichen) Weltseele den Verstand, diese (nun verständige) Weltseele mit der Materie u.s.w." (SCHELLING, 1994, p. 29).

27 A partir de um processo que envolveria os demiurgos assistentes (Timeu, 41a e ss., esp. 41c5 e 42e8) ou deuses mais jovens (Tim., 69c1-5; In Tim., III.110.12-30), equivalentes aos archontes (deuses menores que administram o mundo) noutras obras platônicas (Político, 270d; Leis, X 903b).

28 "Énthen hadên thrốiskei genésis polypoikílou hýlês (...)/ De la jaillit en abondance la source de la Matière três variée (...)" (trad Festugière, tomo 2, livro II, p. 333); "From there (i.e., [the] 'source of sources'), the birth of variegated matter leaps forth (...)" (MAJERCIK, 1989, p. 61); "Thence unceasingly springs the generation of manifold matter (...)" (trad. Michael Share em PROCLUS, 2008, p. 344).

29 Cf. o Fr. 30 dos Oráculos Caldeus. No In Tim., I.388.21, a "Fonte das fontes" parece ser interpretada como o Modelo inteligível, enquanto no contexto da interpretação envolvendo o In Tim, I.451.9-22, a "Fonte das fontes” é claramente o Vivente-em-si. Q.v. PROCLUS, 1967, p. 254 n. 1 e p. 333 n. 1, e PROCLUS, 2008, p. 344, n. 770.

30 Princípio; portanto, não engendrado. 
inteligível -, Proclo sugere ${ }^{31}$ que é a uma matéria com alguma corporeidade ${ }^{32}$ (espécie de "matéria secundária") que essa passagem se refere ${ }^{33}$. Trata-se de um processo que, a partir de uma leitura do Timeu de Platão ajudada pelos comentários de Proclo e Schelling, podemos resumir da seguinte maneira: uma matéria primária (inteligível), não-gerada e sem corpo, acolheria as Formas imanentes. O conjunto destas últimas conforma, de certo modo, a Alma do mundo originária, "abarcadora de todos os Viventes Inteligíveis", dotada de movimento desordenado e, quando associada ao Intelecto, passível de engendrar matéria secundária (sensível), com movimento ordenado. A interação do Demiurgo com as Formas imanentes na Alma do mundo, agora tomada como "abarcadora de toda a série das Formas demiúrgicas", põe em marcha a formação de almas individuais destinadas a se unir a porções de matéria sensível, gerando desse modo entes com composições diferentes de alma e corpo.

No Fr. 35 dos Oráculos Caldeus ${ }^{34}$ aprendemos que Hécate [= o princípio feminino; a Alma do Mundo; o Vivente-em-si (autozỗion)] ${ }^{35}$, a do útero recebedor-de-relâmpagos (prêstereodóchoi kólpoi), é "gerada a partir do Pai ${ }^{36}$ (patroge Noûs)", e no Fr. 32 percebemos que esse Pai é o Demiurgo: "Ele é um trabalhador, (que) é o distribuidor do fogo dador-de-vida/ (que) Ele enche o útero dador-de-vida de Hécate (...)"37. Numa exegese um pouco menos mitológica da relação entre o Vivente-em-si e o Demiurgo, lemos na Teologia Platônica (V.16, 55.22-24) que "com base na [causa] ideal (katà dè tền eidêtikền)" o Vivente-em-si "antecipa a aparição do princípio artífice da totalidade [dos entes] (tền poiêtikền prophainei tôn hólôn archến)"-e podemos dizer, a partir do Comentário ao Timeu (II.360.17-21), que isso transcorre ao nível do Modelo inteligível, anterior ao Demiurgo -, enquanto "com base na causa divina" o Vivente-em-si "recebe a característica específicamente paternal (katà mèn oũn tền theían aitían patrikền elachen idiótêta)" - o que transcorre

31 In Tim., I.388.19-28, no contexto de I.387.9-I.388.28.

32 Ao menos, aquela da espacialidade ou extensão.

33 BRISSON, 2000, p. 329-353; p 351.

34 Damáscio, In Phaed. II, 133.1-6; cf. Proclo In Crat. 58, 19.22.

35 Cf. PROCLUS, 1967, p. 297 n. 1. Q. v. ainda Sarah lles Johnson, Hekate Soteira: a Study of Hekate's Roles in the Chaldean Oracles and Related Literature. Atlanta, Geórgia: Scholar's Press, 1990.

36 O patrikòs noũs, cf. PROCLUS, 1967, p. 297 n. 1

37 In Tim. I.420.11-16 - "[...tà lógiá phêsin hoti] 'ergátis' hoti 'ekdótis' esti 'pyròs zoêphorou' [<autê>],/ (hoti) kai tòn 'zôogónon' plêroĩ 'tễs Hekátes [plêroũs' Hekátes__] kólpon' (...)/ [... Les ORACLES disent qu'elle est] 'Ouvrière', que elle est 'Celle qui produit au jour le Feu porteur de la vie', que elle remplit 'le sein vivifiant d'Hécate' (...)" (PROCLUS, 1967, p. 297 [com reparos no grego a partir de Majercik]); “[... the Oracles say that] it is a worker, (that) is the dispenser of life-giving fire,I (that) it fills up the life-giving womb of Hekate (...)"(MAJERCIK, 1989, p. 61); "[... the Oracles say that] it is 'a worker', that it is 'the bestower of life-bearing fire', that it 'fills the life-producing womb of Hecate' (...)" (PROCLUS, 2008, p. 303). 
ao nível do Modelo intelectivo existente no Demiurgo ${ }^{38}$. Na explicação de Michele Abbate" 39 , "o Vivente-em-si faz aparecer antecipadamente [em potência] aquilo que somente ao nível do Demiurgo se manifesta em todos os efeitos como princípio artífice [poiêtikòn]". Em linguajar mais procleano, o princípio artífice converte-se em ação propriamente paternal quando o Demiurgo "constrói o cosmos agindo através das Formas e dos Princípios racionais [intermediários (demiúrgicos)]"40. Quanto ao desencadeamento do processo geracional, enquanto em Platão uma vontade do Bem - desejoso de que todos os seres lhe sejam na medida do possível semelhantes -, converte a ordem e desordem e põe em marcha o devir (Tim., 29e-30c), em Proclo o desejo pelo Bem é copartícipe do início de tudo: "É através do desejo pelo Bem que os recipientes adiantam-se para receber as causas cósmicas, e é o Bem que leva as formas demiúrgicas a fazerem sua processão em entes secundários, imitando a Fonte de todo o bem, que deu existência a todos os níveis de seres divinos por causa de sua própria bondade, se é legítimo falar $\operatorname{assim}^{41}$ (...)"42 (grifos nossos). O desejo "maternal" (dos recipientes) e a imitação "filial” da Fonte de todo o bem se harmonizam com, e correspondem na prática a, a ação "paternal" que leva as Formas demiúgicas a trazer à existência e organizar os entes sensíveis.

Platão fala no Timeu (29a2-6) que o Cosmos é bonito e seu Construtor (o Demiurgo) é bom porquanto fixou a vista no Modelo eterno. Nas passagens platônicas elencadas por Proclo no In Tim., I.323.23-324.14, identidade e diferença remetem à semelhança ou dessemelhança com o Modelo Inteligível, identificado com a eternidade (estabilidade; fixidez). Se perguntarmos qual natureza é engendrada quando o Demiurgo "desvia a vista" do Modelo eterno que lhe é idêntico "sob um modo inteligível (noêtồs)", encontramos a resposta no próprio Timeu: inveja, defeitos, desordem (30a); limitação quanto à inteligência e à alma (30b); incompletude (30c) e (por antinomia) feiúra e imperfeição (30d). Isso abre caminho para o entendimento da existência na obra procleana de três modos existenciais (I.325.4-9), inteligível/noêtồs (aquele do Modelo), intelectivo/noêrốs (aquele do Demiurgo) e sensível/aisthêtốs (aquele do mundo). Simplificadamente, podemos dizer que o modo existencial do

38 Cf. In Tim. I.419.23-420.5.

39 PROCLO, 2005, p. 1091 n. 205.

40 Theol. Plat., V.16, 55.27-28; cf. In Tim., III.103.5-16 (incluindo passagem do Fr. 37 dos Oráculos Caldeus, reproduzido no In Plat. Parm., 800.18-801.5).

41 O tom de prudência de Proclo tem em vista certas reservas do próprio Platão, como no Timeu, 49a e 52b2, comentadas adiante.

42 In Plat. Parm., 845; PROCLUS, 1992, p. 216. 
mundo origina-se "em seguida" à contemplação do Modelo pelo Demiurgo, lá na ocasião onde essa contemplação converte-se de uma contemplação unitiva pré-temporal (pré-eterna, conforme a leitura que Proclo faz do Timeu 37c-d), inteligível, em uma contemplação disjuntiva intelectiva que se desdobra no tempo (na eternidade) como naturação sensível do/no mundo.

Fazendo nossas as palavras de Pascal Mueller-Jordan ${ }^{43}$, ao abordar o problema da matéria a partir da questão de sua inteligibilidade na mente de alguém que a pensa:

Parece que somos obrigados a admitir que só existe matéria pensável (matière à penser) se a dita matéria já tiver sido formada, e neste caso a matéria pensável não poderia ser matéria absoluta no sentido estrito, mas somente uma matéria secundária (matière seconde), quer seja uma matéria afetada por determinações, que devém matéria secundária, no jogo da linguagem aristotélica, a partir da substância primeira, quer seja uma substância que dá lugar a todas as entidades individuais do mundo sensível para serem o que são, e nada além disso (um tóde ti na linguagem de Aristóteles). Esse é o princípio mesmo do chamado realismo de Aristóteles, que não poderia de modo algum esgotar o mistério que torna esse próprio realismo possível - o postulado de um impensável e enigmático substrato primário ${ }^{44}$ e necessária "matéria indeterminada". A "matéria pensável” não seria, enfim, (...) uma matéria em si, mas uma forma enmattered, como dizem os anglo-saxões - uma forma imanente à matéria.

Poderíamos talvez sugerir que aqui a "matéria indeterminada", substrato primário "impensável e enigmático", remeteria àquele receptáculo 45 (hypodokhé) daquilo que é gerado (Timeu, 49a6, $50 \mathrm{~b} 6$ e ss., 50e5, 51a5, 51a7 e ss. etc.), caracterizado por Platão (52d4-e1) como estando submetido a todas as afecções (... páthê ... páskhousan), ou seja, receptivo a múltiplas determinações e câmbios que caracterizam a diferenciação entre o incriado e o criado, o Ideal e o real, e à complexa relação, só apreensível mediante um "raciocínio bastardo" (52b2), entre o Modelo (inteligível) e as cópias (sensíveis).

Debruçando-se sobre a questão do "terceiro gênero (tríton génos)" "46 (aquele do receptáculo) e de sua relação com o Inteligível, particularmente "desconcertante e obscura" (Timeu, 49a), num capítulo apropriadamente

43 MUELLER-JORDAN, 2008.

$44 \mathrm{Na}$ Met. $\Theta 7,1049 \mathrm{a} 25$, aprendemos que "se existe algo primordial (prỗton) que não possa referir-se a outro como se fosse feito dele, então esse algo será a matéria primária (prótê hýlê)".

45 Princípio de geração (52b2), mãe (métêr, 51a4 e s.) e nutriz (tithếne; 49a6; 52d5; 88d6) daquilo que é gerado (48e-49a); também conhecido como espacialidade ou "espaço substancializado" (khốra; 52a8 ss.), sede (hedra; 52b1) ou lugar (tópos; 52b4).

46 Ao lado dos gêneros do Modelo e da cópia (Timeu 48e e ss. Cf. Tim., 35a, onde o primeiro gênero seria o Ser indivisível que é sempre o mesmo, e o segundo gênero o ser divisível que vem a ser nos corpos). 
intitulado "Rencontre dans l'intervale", Anca Vasiliu se perguntou ${ }^{47}$ sobre o que significa dizer que essa relação repousa sobre uma "participação (metalambánein) que supõe uma recepção, mas também uma certa mudança pelo menos formal [do Inteligível]", interrogando "se será introduzido, nesse ponto, um argumento a favor da existência de uma 'matéria inteligível' da qual participaria em alguma medida o mundo sensível, como interpretaram por seu gosto (à leur gré) os neoplatônicos", ou bem se "Platão hesita ainda entre uma recepção das formas (cópias, representações) sensíveis e uma recepção propriamente dita das formas inteligíveis na 'matéria', como Aristóteles proporá na Física [IV.2]"48 [e também na Metafisica, Z 7, 1032a30-1033a6] ${ }^{49}$. Veremos em seguida, em tratamento breve, de que modo Aristóteles e alguns Neoplatonistas se debruçaram sobre a questão da matéria inteligível na tentativa de elucidar essa relação entre o Demiurgo e o receptáculo que supõe um acolhimento e uma transformação do Inteligível no sensível.

\section{A questão da matéria inteligível em Aristóteles e Plotino}

Aristóteles entende, primeiramente, a "matéria inteligível" num sentido lógico: "Existem dois tipos de matéria, uma inteligível e outra sensível, e existe sempre no $\log _{\text {gos }}{ }^{50}$ uma parte matéria $[\approx \text { potência }]^{51}$ e outra parte [forma, $\left.\approx\right]$ ato" 52 . O problemático entendimento da relação entre matéria e forma é apresentado mediante o seguinte raciocínio ${ }^{53}$ : a matéria está contida na noção (lógos) de forma (ê̂dos) [forma essa que se descreve como figura (schếma)]. Isso remete a um entendimento aristotélico da "matéria inteligível" como "substrato" da diferenciação entre gênero e espécie. Nas palavras de Guthrie, "em lógica, o gênero, sendo menos completamente determinado que sua espécie, pode ser visto como sua matéria (Met., 1058a23-24). 'Assim como da matéria sensível vem a substância concreta, do mesmo modo a espécie vem da matéria

47 VASILIU, 1997, pp. 199-244; p. 233.

48 Cf. PLATON, 1992, p. 250 n. 363, BRISSON, 2005, pp. 15-35. Q. v. ainda Aristóteles, De generatione et corruptione, II.1, 329b13 e ss.

49 Passagem que talvez indique que as formas ou noções (lógoi) teriam sido concebidas por Aristóteles como dotadas de matéria, e não que a matéria teria sido concebida como contendo forma.

50 Aqui, conjunto formado pelo gênero e suas especificações. Aristóteles entende que a matéria deve ser parte de qualquer definição (lógos).

51 Cf. a interpretação de Giovanni Reale no sumário explicativo da Met. H 6, 1045a7-b23 (ARISTÓTELES, 2002, vol. 3 p. 445), e AUBRY, 2002, p. 23.

52 Met. H 6, 1045a34-36.

53 Met. Z 7, 1032a30-1033a5. 
[inteligível] da espécie' (1023b1-2)" "54 . Aristóteles compara o gênero à matéria em mais algumas ocasiões ${ }^{55}$.

$\mathrm{Na}$ Metafísica ${ }^{56}$ Aristóteles diz ainda que "existe uma matéria sensível (aisthetế) e outra inteligível (noêtế)" (Z 11, 1036a9-12). A "matéria sensível" é móvel (1036a10 e ss.) e identifica-se com o que é perceptível e mutável; uma outra matéria seria o "substrato" dos processos inteligíveis (1036b5). Platão já ensinara que os objetos perceptíveis estão sujeitos a mudança ou movimento (Fédon, 78d-79a ; Met. A 6, 987a33 e ss), sendo natural deduzir daí a noção de que é necessário que exista um substrato para realidades universais nãosensíveis (987b6 e ss.), imutáveis. O principal propósito da matéria inteligível é fornecer um substrato para os entes matemáticos fora da matéria perceptível $(Z 11,1037 \mathrm{a} 2-5 ; K 1,1059 \mathrm{~b} 14-21)^{57}$. Esse substrato foi identificado por Ross $^{58}$ simplesmente com a extensão espacial ${ }^{59}$. Há em Aristóteles, portanto, um sentido matemático de "matéria inteligível". Guthrie sugeriu ${ }^{60}$ que esse sentido pode ser um exemplo particular do entendimento de matéria como um gênero.

Procurando em Aristóteles algumas aproximações à questão plotiniana das "duas matérias" podemos perceber que Plotino enfatizou a identificação entre a matéria sensível e a mutabilidade e a saída da ordem, o que veio a culminar no seu entendimento da matéria como indispensável à degradação das formas (ideias), à corrupção das "razões materializadas" (lógoi enyloi) ${ }^{61}$.

No duodécimo tratado das Enéades (II.4) Plotino menciona a existência de dois tipos de matéria, a divina ou inteligível (hýlê theîa, II. 4.5.15; hýlê noêtế, II. 4.5.24) - "lá" junto ao Noûs - ou a sensível - "cá" no plano terreno. Em Plotino, aquilo que em Proclo será apresentado como reflexão sobre a interação entre o Demiurgo e o Modelo aparece separadamente como especulação sobre a processão do Noûs determinando a matéria inteligível ${ }^{62}$ e como especulação sobre a interação entre a Alma e o Intelecto (Noûs) proporcionan-

54 GUTHRIE, 1983, p. 231

55 Met., 1022b5; De an., 417a27.

56 Cf. especialmente Thomas Anderson, "Intelligible Matter and Objects of Mathematics in Aristotle". New Scholasticism, 43, 1969: 1-28; Stephen Gaukroger, "Aristotle on Intelligible Matter". Phronesis (Assen), 25 (2), 1980; 187-197.

57 Cf. Met. K3, 1061a28-35.

58 ROSS, 1995, p. 106.

59 Em Tomás de Aquino, por sua vez, a matéria inteligível corresponde ao gênero da matemática identificado com a quantidade (Cf. Dennis dês Chennes. Life's Form: Late Aristotelian Conceptions of the Soul. Ithaca: Cornell University Press, 2000, p. 116).

60 GUTHRIE, 1983, pp. 231-2.

61 Ou "determinações na matéria”, que é como Maria Cecília Gomes dos Reis, comentando o De anima I.1, 403a24, traduz essa expressão (Aristóteles, De Anima. São Paulo: editora 34, 2006, p. 151).

62 Cf. especialmente En. Il.4.5.24 e 33-35; V.2.1.9-13 e 19-20. 
do a gênese da matéria sensível ${ }^{63}$. Encontramos em Plotino uma identificação do Demiurgo com o Noûs (V.1.8.5; dêmiourgos gàr ho Noûs autôi), resultado de uma peculiar interpretação do Filebo ${ }^{64}$, onde o Nô̂s aparece como causa e onde é um qualificativo ("Inteligência") do Demiurgo.

Conforme diversos intérpretes, a matéria inteligível ou divina equivale à "Díade indefinida (aóristos dyás)" (V.1.5.14), identificada com a processão do $N o \hat{u} s^{65}$. No pensamento plotiniano observa-se uma fusão entre a "Díade indefinida" da tradição platônica com a "matéria inteligível" aristotélica. John Michael Rist ${ }^{66}$ mostrou que a "Díade indefinida" plotiniana corresponde à primeira efusão do Uno (saindo da unidade na identidade para a distinção na alteridade; En., II.4.5.28-39) e constitui a base do mundo inteligível, plano da união das Formas com a matéria inteligível. Plotino diz (II.4.5, 28-33, esp. 2930) que a archế da matéria inteligível é constituída por diferença e movimento - condições que preparam a naturação da matéria sensível.

Por questões de lugar e de ocasião não me alongarei aqui sobre a questão da "Díade indefinida", com raízes no Filebo (23c1 e ss.) e no Timeu ${ }^{67}$ de Platão e na Metafísica ( $Z$ 10, 1035a9 e $Z$ 11, 1037a4; H 6, 1045a33 e ss.) de Aristóteles. Por ora, é importante apontar que uma fusão entre a "Díade indefinida" da tradição platônica e a "matéria inteligível" aristotélica já ocorrera ${ }^{68}$ [identificando-se também com o princípio do Ilimitado ou do mais (mâllon) e do menos (hêtton) no Filebo, 23c-26d, e com a ideia do receptáculo no Timeu, 48e-52d ${ }^{69}$ no pensamento do Neopitagórico Moderato de Gades (floruit 80-90 d.C.), sob a forma da "quantidade (posótêta)" carente de lógoi e de formas (lógôn kai eidônn), descrita como amorfa (amorphon), indiferenciada (adiaíreton) e sem figura (aschêmátiston), embora receptiva a qualidade (poiótêta) [forma, diferenciação e figura], que se segue ao Lógos Unitário (heniaîos lógos) ${ }^{70}$. Em suas Lições sobre o Pitagorismo (Pythagorikai Scholai), Moderato - a quem

63 Acompanhando O'BRIEN, 1991; O'BRIEN, 1993, pp. 24-27; O'BRIEN, 2008, pp. 181-3. As passagens plotinianas mais importantes são En. III, 9, 3.7-16; III, 4, 1.1-16.

64 BRÉHIER, 1928, nota sobre En., V.1.13.

65 RIST, 1962; GERSON, 1994, p. 101; NIKULIN, 1998; STAMATELLOS, 2007, p. 61; KORRIGAN, 1996, p. 113 e ss.

66 RIST, 1961, p. 155 e ss.; 1962, passim; 1967, p. 219 e ss.

67 REALE, 1997, pp. 463-471.

68 DILLON, 1977, pp. 346-351; KAHN, 2001, pp. 105-110.

69 TURNER, 2001, pp. 371-372.

70 Cf. o fragmento das Lições sobre o Pitagorismo, de Moderato, preservado por Simplício, In Phys., 230.34231.24 DIELS, 1882, Fr. 236F SMITH, 1994, comentando um tratado (perdido) de Porfírio, Perì hýlês/Sobre a matéria. Cf. ainda DILLON, John. The Middle Platonists. Ithaca: Cornell University Press, 1977, pp. 347349; THOMASSEN, Einar. The spiritual Seed: the church of the "Valentinians". Leiden: E. J. Brill, 2006, pp. 272-273. 
Porfírio faz menção (Vita Pyth., 48-53) ${ }^{71}$ e a cuja obra Plotino deve ter tido acesso - expôs um sistema de princípios que parece derivado das duas primeiras deduções da segunda metade do Parmênides de Platão e que antecipa importantes ideias de Plotino ${ }^{72}$. Nesse sistema existem três Unos - o primeiro está acima do ser (Parm., 137c-142a), o segundo é identificado com as Formas e é acompanhado pela Díade indefinida (ou seja, a matéria inteligível), e o terceiro é identificado com a alma.

Para a ideia plotiniana da matéria sensivel, por outro lado, muito parece ter contribuído a associação no Sofista entre os entes sensíveis e o não-ser conforme definido pelo estrangeiro de Eléia: os entes sensíveis, à diferença dos inteligíveis, devem participar no Ser e, ademais, participar também em alguma forma de alteridade ou "não-ser" - aquela parte do "outro" que se opõe ao ser de cada coisa (Sofista, 258d7-e3) -, alteridade essa que torna possível a distinção entre os inteligíveis e os entes sensíveis.

\section{A "matéria inteligível" e o elemento dos astros}

Percebe-se no De generatione animalium $^{73}$ (II.3, 736b29-737a7) a relação da dýnamis de cada alma com "um corpo diferente e mais divino que aquele dos chamados elementos" (736b29-31), um corpo de certa forma ligado a um pneûma dotado de uma natureza análoga ao elemento dos astros (737a1). Esse pnê̂ma eterno e imperecível" ${ }^{74}$ seria constituído de um "quinto elemento" que a tradição neoplatônica muitas vezes tomou como uma corporeidade vinculada à matéria inteligível. Paul Moraux (col. 1173) notou que a quinta essentia desempenhou na tradição posterior um importante papel como substância intermediária entre a realidade material e a imaterial, mas negou com veemência (col. 1206) a identidade entre aquele "corpo diferente e mais divino" do De generatione animalium e o "corpo astral" que aparece na tradição exegética do Timeu, 41d4-42a1 - passagem que fundamenta toda a especulação ocidental sobre o "veículo" (ochêma) ${ }^{75}$ ou "veículos" (ochếmata) da

71 Nessa passagem Porfírio mostra Moderato argumentando que os Pitagóricos usavam os números para possibilitar um entendimento claro acerca das Formas incorpóreas e dos Primeiros Princípios, que não poderiam ser comunicados em palavras.

72 Cf. DILLON, 1977, pp. 346-351; KAHN, 2001, pp. 105-110.

73 ARISTOTLE, 1965.

74 Cf. MORAUX, 2003, colunas 1171-1263; BOS, 2003, passim. passim.

75 Cf. Proclo, El. theol., 209, In Tim., III.60.2-16; 72.14; 85.4; 236.31 e ss. e 297-8; In Remp., II, 300. 
alma"76. Mais recentemente, contudo, Abraham Bos ${ }^{77}$ concluiu que o ponto de vista de Moraux estava incorreto. Encontramos no De mundo ${ }^{78}$ (4, 394b9-12), atribuído a Aristóteles por Alexandre de Afrodísias, a definição do pneûma como "a substância animada e geradora de vida que permeia [os corpos] das plantas e criaturas vivas", e no De generatione et corruptione (II.10, $336 \mathrm{~b} 31$ e ss.) Aristóteles chama o processo de geração na esfera sublunar de endelechê, e isso ocorre "porque o poder de cada alma 'tem algo do' elemento astral, de modo que a continuidade [endelécheia] das espécies está garantida"79. Bos, então, acredita que Aristóteles postulou em sua "filosofia da natureza animada" $" 80$ uma realidade em três níveis ${ }^{81}$, sendo o mais elevado aquele do Intelecto ou alma incorpórea como causa final e entelécheia ${ }^{82}$ do cosmos e o menos elevado aquele da matéria dos elementos (que podemos aproximar à "matéria sensível" de Plotino), existindo entre eles um nível intermediário correspondente ao "quinto elemento" (que podemos aproximar à "matéria inteligível" de Plotino) como causa eficiente e endelécheia ${ }^{83}$ "continuidade"; "persistência") que realiza o plano divino, e que Cícero entendeu ${ }^{84}$, estudando Aristóteles, como sendo a matéria das estrelas, dos planetas e também da alma humana.

\section{A questão da matéria inteligível em Proclo}

No seu Comentário ao primeiro livro dos Elementos de Euclides (Prólogo I ${ }^{85}, 15$ e 16) Proclo tem bem clara a distinção entre a Alma e a matéria ${ }^{86}$ : a

76 Para Proclo, os ochếmata - "corpos primários" perpétuos, não-gerados e incorruptíveis (El. theol., 196) e ademais provisórios (El. theol., 209) - limitam, ao mesmo tempo separando e intercomunicando, os distintos níveis da alma no cosmos, resguardando sua continuidade e moderando "toda desordem advinda da matéria" (In Tim., III.262.18-19). Os ochếmata fazem da alma tanto "cidadã do universo (politidas toû pántos)" (In Tim., III.266.6) quanto “cidadã da geração" (III.297.4; 298.29).

77 BOS, 2003, p. 161.

78 Cf. REALE e BOS, 1995, pp. 285-88.

79 BOS, 2003, p. 272, remetendo ao De generatione animalium, II.3, 736b29-737a7.

80 Com uma unidade que Bos apregoa existir entre o De anima, os tratados biológicos e as obras perdidas (das quais só fragmentos e menções indiretas nos chegaram).

81 BOS, 2003, cap. 14 e p. 370-1.

82 "Ser-no-fim", "continuidade na completude" ou "existência no persistir" - de enteles, "complet[ad]o; perfeito; crescido", e echein, "ser por permanecer; ficar; manter-se" [acompanhamos de perto Joe Sachs na introdução à sua tradução em Aristotle, Metaphysics (Santa Fe, NM: Green Lyon Press, 1999), e em J. Sachs, "Aristotle (384-322 BCE): Motion and its Place in Nature". Internet Encyclopaedia of Philosophy, 2006, disponível em <www.iep.utm.edu/a/aris-mot.htm>. Cf. ainda Beátrice. Bakhouche"La définition aristotélicienne de l'âme dans vuelques textes latins : endelecheia ou entelecheia ?".Ars Scribendi, 4, 2006: 1-17, em < http://ars-scribendi.ens-Ish.fr/IMG/pdf/Bakhouche.pdf > ].

83 Por causa de seu característico movimento contínuo, segundo Cícero.

84 Acad. 1, 7, 26; Tusc. 1, 10, 22 ; 1, 17, 41; 1, 26, 65 até 27, 66; 1, 66-67.

85 O primeiro prólogo trata da matemática em geral.

86 PROCLUS, 1970, pp. 13-14. 
Alma é o locus das realidades primárias, as Ideias/Formas ${ }^{87}$, preeminentemente reais e essenciais; a matéria é o locus das realidades secundárias, as Ideias/ Formas corporificadas ou derivativas. A Alma é a copartícipe primária, e ademais semelhança e réplica exterior, do Noûs e da Existência inteligível, e complemento $^{88}$ (plếroma) das Ideias/Formas; a matéria é potencialmente todas as coisas e não gera nenhuma das Ideias/Formas corporificadas. Por outro lado, na mesma obra (Prólogo II ${ }^{89}, 49.4$ e ss.) Proclo se questiona acerca do estatuto ontológico da matéria geométrica (tên geômetrikên hylên). Se as figuras de que falam os geômetras são percebidas pelos sentidos e, portanto, vinculadas à matéria sensível, como podem elas levar-nos a pensar a imaterialidade dos Inteligíveis? Não encontramos entre os entes sensíveis pontos sem largura, linhas irretocáveis e ângulos perfeitos, encontradiços nos entes geométricos. Ademais, como poderiam ser constantes as conclusões da geometria se os entes a que se referem se localizassem na mutável matéria sensível? Por outro lado, se os elementos da geometria estivessem fora da matéria (exô tẽs hylês esti ta hypokeimena têi geômetriai), sem qualquer relação com os entes sensíveis, como poderiam ter partes, corpo ou magnitude? Proclo tem por certo que os lógoi geométricos "apresentam magnitute, volume e extensão, em virtude da matéria que é seu receptáculo (tên hylên hypodochên), um receptáculo que acolhe o indivisível de uma maneira dividida, o inextenso através da extensão, e o imóvel como móvel" (49.27-50.2).

Detenhamo-nos um instante para apontar que "receber o inextenso através da extensão", e expressões correlatas, são metáforas empregadas para se referir à matéria inteligível, que se estende sem dispersar nem separar (In Euclid, 52.20-53.1 $)^{90}$, como seria o caso da matéria dos entes matemáticos e geométricos. Permitindo uma extensão que não dispersa, a matéria inteligível dá condições para pensarmos uma divisibilidade que não esfacela e anula, e que torna possível contato, comparações de tamanho e fracionamentos. Proclo conclui que existem dois tipos de matéria, "como Aristóteles diz em algum lugar - a matéria dos entes ligados à sensação e a matéria dos entes imaginais ${ }^{91}$ (tôn phantastôn $)^{92}$-, e devemos admitir que o universal correspondente (ditton einai to katholou) também é duplo - [ora] sensível, porquanto participado por

87 Como dizem Morrow e Dillon (PROCLUS, 1992, p. 612 n.), Proclo emprega idéa e eidos de um modo um tanto indiscriminado.

8816.27 e ss., $17.6,36.15,45.22,55.18,62.23$.

89 O segundo prólogo trata da geometria.

90 PROCLUS, 1873, p. 52. Cf. Jean Trouillard, “Le symbolisme chez Proclos". Dialogues d'histoire ancienne, 7 (1), 1981: 297-308.

91 Empregamos "imaginal" no sentido dos usos de Henri Corbin para imaginalis.

92 Cf. MacISAAC, 2001a e 2001b, cap. IV. 
coisas sensíveis, [ora] imaginal, porquanto existe na multiplicidade da phantasia" (51.15-17). MacIsaac ${ }^{93}$ pensa que "a phantasia tem em si um universal que é diferente do universal nos objetos dos sentidos, mas também é diferente do universal na diánoia, e esse universal na phantasia encontra-se por sua vez em uma matéria que, do mesmo modo, está entre a matéria do sensível e a imaterialidade da diánoia ${ }^{94}$ ". Devemos, contudo, recordar que estamos novamente no domínio dos raciocínios aproximativos, analógicos ou bastardos.

Proclo considera a noção de matéria inteligível como produto de um entendimento confuso sobre a ideia de vida ou potência no plano superior:

(...) ao meu juízo, todo ser e toda essência (pân to on kaì hế ousía) tem potências conaturais (symphyeîs) porquanto participam da não-limitação (apeirías), e derivam sua realidade (hyparxis) do limite (pératos), mas sua potência do ilimitado (apeiron). E o ser não é nada mais que uma mônada com potências múltiplas, e realidade feita múltipla (plêthynoménê), e por isso o ser é uno-múltiplo (hen pollà to on). Os muitos, contudo, existem de modo secreto (kryphíos) e indistinto/sem separação (adiakritôs) nos primeiros entes, mas distintos/separados (diêirêménôs) nos segundos. De fato, quanto mais o ser é congênito (syngenésteron) com o Uno, tanto mais ele oculta sua multiplicidade e se autodefine somente com base em sua unidade. E me parece que é com o intento de por à luz esses aspectos que os seguidores de Plotino (hoi peri Plotînôn) frequentemente consideram o ser como composto de forma e matéria inteligível, e consideram a forma como estando organizada de modo análogo ao Uno e à realidade (hyparxis), mas a potência como análoga à matéria ${ }^{95}$. E se é isso que pretendem dizer, com razão o dizem; mas se ao invés disso atribuem à essência inteligível uma natureza sem figura (amorphón), sem forma (aneídeon) e indefinida (aóriston) me parece que se afastam das concepções platônicas sobre esse assunto. De fato, o ilimitado não é a matéria do limite, mas sua potência, nem o limite é a forma do ilimitado, mas sua efetiva realidade. Mas o ser consiste de ambos, porquanto não somente permanence no Uno, mas recebe em si uma multitude de unidades (henádôn) e de potências que se misturam de modo a formar uma única essência (Theol. Plat., III.9, 39.15-40.9 $)^{96}$.

Nesta passagem, interpretamos "os primeiros entes", nos quais "muitos [outros] (...) existem de modo secreto e sem separação", como sendo as Formas imanentes na Alma do mundo, dotada a priori de uma potência análoga à matéria inteligível. Nesta, a forma se organiza de modo análogo ao Uno, isto é, ao Inteligível, que é ilimitado. A expressão "o ilimitado não é a matéria do limite, mas sua potência, nem o limite é a forma do ilimitado, mas sua efetiva realidade" significa que o Intelecto é a potência da matéria, e a matéria é o

93 MacISAAC, 2001a, p. 126.

94 MacISAAC, 2001a, nota 6, recorda que para Proclo os objetos da matemática são dianoéticos, mas os objetos da matemática pertencem a uma classe mais baixa.

95 Cf. Plotino, En. II 4 (12), 2-5.

96 PROCLO, 2005, pp. 352 e 354 (grego), 353 e 355 (italiano). 
Intelecto em ato; isso se comprova pela afirmação procleana de que "algo que tem matéria, seja Inteligível ou sensível, tem um limite que é determinado a partir do exterior" (In Euclid, 142). Não obstante essa continuidade (que bordeja a identidade) entre o Inteligível e o sensível, a Alma - que Proclo explicitamente qualifica de copartícipe e desdobramento do Noûs (In Euclid, Prólogo I, 15 e 16) - faz a mediação entre o Intelecto, a matéria inteligível e a matéria sensível, e em seu comentário ao Timeu, 35a1-4, Proclo situa a Alma entre o completamente indiviso (amériston) e o dividido (meristón) (In Tim., II.139.9-143.21).

Apropriando-nos de uma distinção postulada por Frans de $\mathrm{Haas}^{97}$, pensamos que a "matéria inteligível", no entendimento que Proclo, seria dotada de "extensionalidade", espacialidade carente de magnitude e limite, enquanto na matéria sensível os entes têm "extensão", entendida como comprimento, largura e profundidade particular (limitados), definindo um certo volume ou magnitude. Por ser carente de limite, portanto, a "matéria inteligível" não deveria legitimamente ser chamada de matéria, mas esse nome lhe é aplicado, mediante raciocínio impreciso e aproximativo, por conta da capacidade da "matéria inteligível" de limitar-se interiormente e delimitar aquilo que surge dela como "matéria sensível".

\section{Conclusão}

Um longo e sinuoso percurso se estende da questão Platônica sobre a relação entre o Demiurgo e o modelo do mundo criado até a especulação aristotélica e platonista sobre a existência de dois tipos de matéria, inteligível e sensível. Os exegetas platônicos construíram um elaborado discurso sobre uma corporeidade intermediária para tentar esclarecer como se daria a animação do sensível por uma realidade inteligível, a alma ${ }^{98}$. Entre os neoplatonistas, teorias acerca da quinta essentia e do(s) "veículo(s) da alma" ajudaram a explicar a interação entre o inteligível e o sensível e contribuíram para uma melhor representação da possibilidade da "implantação" de uma alma imortal num corpo perecível, vindo por outro lado, no entanto, a inflamar a duradoura

97 DE HAAS, 1997, pp. 47-8. DE HAAS (1997, p. 52) enxerga na "natureza que recebe todos os corpos" e "que tem de receber devidamente, muitas e muitas vezes e em cada parte de si, todas as semelhanças das coisas inteligíveis e eternas" do Timeu (51a2; 51a1-3) um locus de extensionalidade.

98 Cf. Stéphane Toulouse, "Le véhicule de l'âme chez Plotin: de la réception d'une hypothèse cosmologique à l'usage dialectique de la notion". Études platoniciennes III - L'âme amphibie - Études sur l'âme selon Plotin. Paris: Les Belles Lettres, 2006, pp. 103-128. 
polêmica acerca da preexistência da alma ${ }^{99}$. Essas questões, reapresentadas em diversos momentos da tradição filosófica ocidental, ainda preservam muito de sua problematicidade, por causa da profundidade de suas sondagens e implicações e não menos por conta de sua vinculação com passagens e raciocínios que ainda preservam sua aura de obscuridade.

\section{Referências}

ARISTÓTELES. Metafísica, 3 vols. (vol. 1 Ensaio introdutório; vol. 2 Texto grego com tradução ao lado; vol. 3 Sumário e Comentários), ed. G. Reale, trad. M. Perine. São Paulo: Loyola, 2002 (reimpr. 2005).

ARISTOTLE. De Generatione Animalium, trad. H. J. Drossaart Lulofs. Oxford: Clarendon Press, 1965.

AUBRY, G. "L'ontologie aristotélicienne comme ontologie axiologique: proposition de lecture de la Métaphysique". Philosophie antique, 2, 2002: 5-32.

BOS, A. P. The Soul and Its Instrumental Body: a reinterpretation of Aristotle's philosophy of living nature. Leiden: Brill, 2003.

BRÉHIER, E. La Philosophie de Plotin. Paris: Boivin, 1928.

BRISSON, L. "Le commentaire comme prière destinée à assurer le salut de l'âme. La place et le rôle des Oracles Chaldaïques dans le Commentaire sur le Timée de Platon par Proclus". Em: Marie-Odile Goulet-Cazé et al. (eds.), Le commentaire entre tradition et innovation (Actes du Colloque international de l'Institut des traditions textuelles. Paris e Villejuif, 22-25/09/1999). Paris: Vrin, 2000, p. 329-353.

BRISSON, L. "La theorie de la 'matière' dans le Timée de Platon et sa critique par Aristote dans la Physique”. Em: Cristina Viano (ed.), L'alchimie et ses racines philosophiques: La tradition grecque et la tradition arabe. Paris: Vrin, 2005, pp. 15-35.

DE HAAS, F. A. J. John Philoponus' new definition of Prime Matter: aspects of its background in Neoplatonism and the ancient commentary tradition. Leiden: E. J. Brill, 1997.

DIELS, H. Simplicii in Aristotelis physicorum libros octo commentaria, 2 vols. (Commentaria in Aristotelem Graeca, vol. IX - libros quattuor priores comment.; vol. X - libros quattuor posteriores comment.). Berlim: Reimer, 1882 e 1895 (reimpr. Berlim/N. Iorque: Walter de Gruyter, 2001).

DILLON, J. The Middle Platonists. Ithaca: Cornell University Press, 1977.

GERSON, L. P. Plotinus (The Arguments of the Philosophers), $2^{\mathrm{a}}$ ed. Londres/N. Iorque: Routledge, 1994.

GUTHRIE, W. K. C. A History of Greek Philosophy, vol. VI-Aristotle, an encounter, $2^{\mathrm{a}}$ ed. Cambridge: Cambridge University Press, 1983 (reimpr. 1990). 
KAHN, C. H. Pythagoras and the Pythagoreans. Indianapolis: Hackett, 2001. KORRIGAN, K. "Essence and existence in the Enneads". Em: Lloyd P. Gerson (ed.), The Cambridge Companion to Plotinus. Cambridge/N. Iorque/Melbourne: Cambridge University Press, 1996, pp. 105-129.

LONGIN. Fragments, Art rhétorique, ed. M. Patillon e L. Brisson. Paris: Budé, 2001.

MAJERCIK, R. D. The Chaldean Oracles: text, translation and commentaries. Leiden: E. J. Brill, 1989.

MacISAAC, G. "Phantasia between soul and body in Proclus' Euclid Commentary". Dionysius, 19, 2001: 125-136 (= 2001a)

MacISAAC, G. The Soul and discursive reason in the philosophy of Proclus. Tese de doutoramento em filosofia, University of Notre Dame, Indiana, 2001 (=2001b).

MORAUX, P. "Quinta essentia”. Em: A.-F. Pauly, G. Wissowa (eds.), Realenzyklopädie der classischen Altertumwissenschaft, XXIV (I), Halb Band XLVII. Stuttgart: J. B. Metzler, 1963.

MUELLER-JORDAN, P. “On ne peut penser la matière, que s'il y a matière à penser". Em: Françoise Daviet-Taylor (org.), Penser le monde: puissance et impuissance du langage. Comunicação à Journée d'étude du CPER, 13/06/2008, Université d'Angers).

Disponível em $<$ www.theolarge.fr/spip.php?article90 $>$; acesso em 04/03/2009.

NIKULIN, D. "Intelligible Matter in Plotinus". Dyonisius, XVI, 1998: 85-114.

O'BRIEN, D. Plotinus on the Origin of Matter. Nápoles: Bibliopolis, 1991.

O'BRIEN, D. Theodicée plotinienne, théodicée gnostique. Leiden: Brill, 1993.

O'BRIEN, D. "Plotinus on matter and evil". Em: Lloyd P. Gerson (ed.), The Cambridge Companion to Plotinus. Cambridge/N. Iorque/Melbourne: Cambridge University Press, 2008, pp. 171-195.

PLATÃO. Timeu. Em: Timeu. Crítias. O Segundo Alcibíades. Hípias Menor, trad. C. A. Nunes. Belém: EDUFPA, 2001, pp. 49-147.

PLATON. Timée, Critias, trad. L. Brisson. Paris: G. F. Flammarion, 1992.

PLOTINO. Enneadi (ed. bilíngue), trad. G. Faggin. Milão: Bompiani, 2000.

PORFIRIO. Porphyrii in Platonis Timaeum Comentariorum Fragmenta, ed. A. R. Sodano. Nápoles: Istituto della Stampa, 1964.

PROCLO. Teologia Platonica (grego/italiano), ed. M. Abbate. Milão: Bompiani, 2005.

PROCLUS. In primum Euclidis Elementorum librum commentarii, ed. G. Friedlein. Leipzig: Teubner, 1873.

PROCLUS. A Commentary on the first book of Euclid's Elements, trad. G. R. Morrow. Princeton (N. Jérsei): Princeton University Press, 1970.

PROCLUS. Commentary on Plato's Parmenides, trad. G. R. Morrow e J. M. Dillon. Princeton (N. Jérsei): Princeton University Press, 1992.

PROCLUS. Commentaire sur le Timée, 5 tomos, trad. e notas E. J. Festugière. Paris: Librairie Philosophique J. Vrin, 1967 (reimpr. 2006). 
PROCLUS. Commentary on Plato's Timaeus (4 vols.), Volume II, Book 2: Proclus on the Causes of the Cosmos and its Creation, trad. e notas D. T. Runia e M. Share. Cambridge/N. Iorque/Melbourne: Cambridge University Press, 2008.

PROCLUS. Commentary on Plato's Timaeus (4 vols.), Volume III, Book 3 Part 1: Proclus on the World's Body, trad. e notas D. Baltzly. Cambridge/N. Iorque/Melbourne: Cambridge University Press, 2007.

REALE, G., BOS, A. P. Il tratato 'Sul cosmo' per Alessando atribuito ad Aristotele (ed. bilíngue), $2^{\mathrm{a}}$ ed. Milão: Vita e Pensiero, 1995.

REALE, G. Para uma Nova Interpretação de Platão, trad. M. Perine a partir da $14^{\mathrm{a}}$ ed. italiana (1991). São Paulo: Loyola, 1997.

RIST, J. M. "Plotinus on Matter and Evil". Phronesis, 6 (2), 1961: 154-166.

RIST, J. M. "The Indefinite Dyad and Intelligible Matter in Plotinus". Classical Quarterly, 12, 1962: 99-107.

RIST, J. M. Plotinus - The Road to Reality. Cambridge/Londres/N. Iorque/Melbourne: Cambridge University Press, 2009.

ROSS, W. D. Aristotle, 6ª ed. N. Iorque: Routledge, 1995.

SCHELLING, F. W. J. "Timaeus" (1794) [Schellingiana; Bd. 4], ed. Hartmut Buchner. Stuttgart/Bad Cannstatt: Frommann-Holzbog, 1994.

SIORVANES, L. Proclus: Neo-Platonic Philosophy and Science. Edimburgo: Edinburgh University Press, 1996.

SMITH, A. Porphyrii Philosophi Fragmenta. Stuttgart/Leipzig: Teubner, 1994.

STAMATELlOS, G. Plotinus and the Presocratics: a philosophical study of Presocratic influences in Plotinus' Enneads. Nova Iorque: State University of New York Press, 2007.

TOULOUSE, S. "Le véhicule de l'âme chez Plotin: de la réception d'une hypothèse cosmologique à l'usage dialectique de la notion". Études platoniciennes III - L'âme amphibie - Études sur l'âme selon Plotin. Paris: Les Belles Lettres, 2006. VASILIU, A. Du Diaphane: image, milieu, lumière dans la pensée antique et médiévale. Paris: Vrin, 1997. 